\title{
Guiding Uniformly Distributed Li Ion Flux by Lithiophilic Covalent Organic Framework Interlayers for High-Performance Lithium Metal Anodes
}

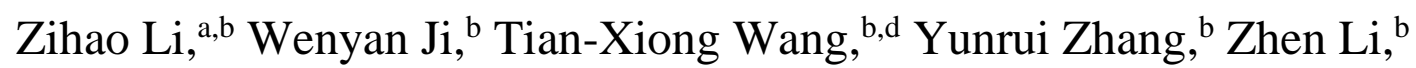
Xuesong Ding, ${ }^{*, b}$ Bao-Hang Han, ${ }^{*, b, d}$ Wei Feng*,a,c

${ }^{a}$ School of Material Science and Engineering, Tianjin University, Tianjin 300072, China

${ }^{b}$ CAS Key Laboratory of Nanosystem and Hierarchical Fabrication, CAS Center for Excellence in Nanoscience, National Center for Nanoscience and Technology, Beijing 100190, China

${ }^{c}$ Collaborative Innovation Center of Chemical Science and Engineering, Tianjin 300072, China

${ }^{d}$ University of Chinese Academy of Science, Beijing 100049, China 
This PDF file includes:

\section{Tables S1 to S4}

Fig. S1 to S21 
Table S1. The Zeta potential and average size of TpTt dispersion before and after LiTFSI addition.

\begin{tabular}{|c|c|c|}
\hline TpTt Dispersion & Zeta Potential (mV) & Average Size (nm) \\
\hline Before LiTFSI Addition & -34.5 & 1123 \\
\hline After LiTFSI Addition & -2.1 & 123 \\
\hline
\end{tabular}

Note: LiTFSI is lithium bis(trifluoromethane)sulfonamide.

Table S2. The electrochemical parameters of symmetric batteries with and without TpTt protecting layer, and lithium transfer number calculated from potentiostatic direct current (DC) polarization and alternating current (AC) impedance spectra.

\begin{tabular}{|c|c|c|c|c|c|}
\hline & $R_{0}(\Omega)$ & $R_{\mathrm{S}}(\Omega)$ & $I_{0}(\mathrm{~mA})$ & $I_{\mathrm{S}}(\mathrm{mA})$ & $t_{\mathrm{Li}^{+}}$ \\
\hline $\mathrm{PP}$ & 98.88 & 101.78 & 0.0932 & 0.0842 & 0.55 \\
\hline $\mathrm{TpTt} @ \mathrm{PP}$ & 65.76 & 62.33 & 0.0838 & 0.0748 & 0.84 \\
\hline
\end{tabular}

Note: PP is polypropylene. $R_{0}$ and $R_{\mathrm{S}}$ refer to the interfacial resistance before and after AC impedance. $I_{0}$ and $I_{\mathrm{s}}$ represent the current value in initial and steady state under a polarization potential of $10 \mathrm{mV}$ in DC process. $t_{\mathrm{Li}^{+}}$is the lithium transfer number, and the value is calculated as follows.

$$
t_{\mathrm{Li}^{+}}=\frac{I_{\mathrm{S}}\left(\Delta V-I_{0} R_{0}\right)}{I_{0}\left(\Delta V-I_{\mathrm{S}} R_{\mathrm{S}}\right)}
$$


Table S3. The comparison of the symmetric $\mathrm{Li}-\mathrm{Li}$ cells for different modifications at a current density of $0.5 \mathrm{~mA} \mathrm{~cm}{ }^{-2}$ and capacity of $0.5 \mathrm{mAh} \mathrm{cm}^{-2}$.

\begin{tabular}{|c|c|c|c|}
\hline $\begin{array}{c}\text { Cycling } \\
\text { time }(\mathrm{h})\end{array}$ & $\begin{array}{c}\text { Voltage } \\
(\mathrm{mV})\end{array}$ & Modifications & References \\
\hline 350 & 38 & Magnetic field treated Li sheets & {$[\mathrm{S} 1]$} \\
\hline 400 & 30 & $\mathrm{HIO}_{3}$ chemical pretreated Li sheets & {$[\mathrm{S} 2]$} \\
\hline 500 & 100 & $(\mathrm{PVDF}-\mathrm{HFP}) / \mathrm{ZnO}$ composite membrane & {$[\mathrm{S} 3]$} \\
\hline 900 & $*$ & Magnetron sputtering amorphous $\mathrm{Li}_{3} \mathrm{PO}_{4}$ & {$[\mathrm{~S} 4]$} \\
\hline 1000 & $*$ & protective layer & {$[\mathrm{S} 5]$} \\
\hline 1000 & $17-31$ & Cu99Zn alloy & {$[\mathrm{S} 6]$} \\
\hline $\mathbf{2 4 5 0}$ & $\mathbf{1 2}$ & Lilicate coating Li sheets & This work \\
\hline
\end{tabular}

* The relevant result is not provided in the literature. 
Table S4. The comparison of the symmetric $\mathrm{Li}-\mathrm{Li}$ cells for different modifications at a current density of $1.0 \mathrm{~mA} \mathrm{~cm}{ }^{-2}$ and capacity of $1.0 \mathrm{mAh} \mathrm{cm}^{-2}$.

\begin{tabular}{|c|c|c|c|}
\hline $\begin{array}{c}\text { Cycling } \\
\text { time }(\mathrm{h})\end{array}$ & $\begin{array}{c}\text { Voltage } \\
(\mathrm{mV})\end{array}$ & Modifications & References \\
\hline 300 & 10 & Semiconductive microporous framework & {$[\mathrm{S} 7]$} \\
\hline 400 & 20 & Polar PAN protecting layer & {$[\mathrm{S} 8]$} \\
\hline 400 & 20 & Lignosulfonate coated separator & {$[\mathrm{S} 9]$} \\
\hline 400 & 23.3 & Dual-engineered separator & {$[\mathrm{S} 10]$} \\
\hline 400 & 40 & Lithium silicide protecting layer & {$[\mathrm{S} 11]$} \\
\hline 450 & $*$ & MgF//graphene framework & {$[\mathrm{S} 12]$} \\
\hline 500 & 30 & Reduced graphene oxide@ Li & {$[\mathrm{S} 13]$} \\
\hline 500 & 30 & Nitrogen and sulfur co-doped carbon paper & {$[\mathrm{S} 14]$} \\
\hline 550 & $*$ & Hybrid interphase of C60 and Mg & {$[\mathrm{S} 15]$} \\
\hline 600 & 20 & $\begin{array}{c}\text { Li4.4 Sn encapsulated in hollow graphene } \\
\text { spheres }\end{array}$ & {$[\mathrm{S} 16]$} \\
\hline 744 & $*$ & Carbon fiber network & {$[\mathrm{S} 17]$} \\
\hline 800 & $54-66$ & Copper nitride nanowires & {$[\mathrm{S} 18]$} \\
\hline 850 & $*$ & $\begin{array}{c}\text { Fluorinated hybrid solid electrolyte } \\
\text { interphase }\end{array}$ & {$[\mathrm{S} 19]$} \\
\hline 1000 & 14 & This work \\
\hline
\end{tabular}

*The relevant result is not provided in the literature. 


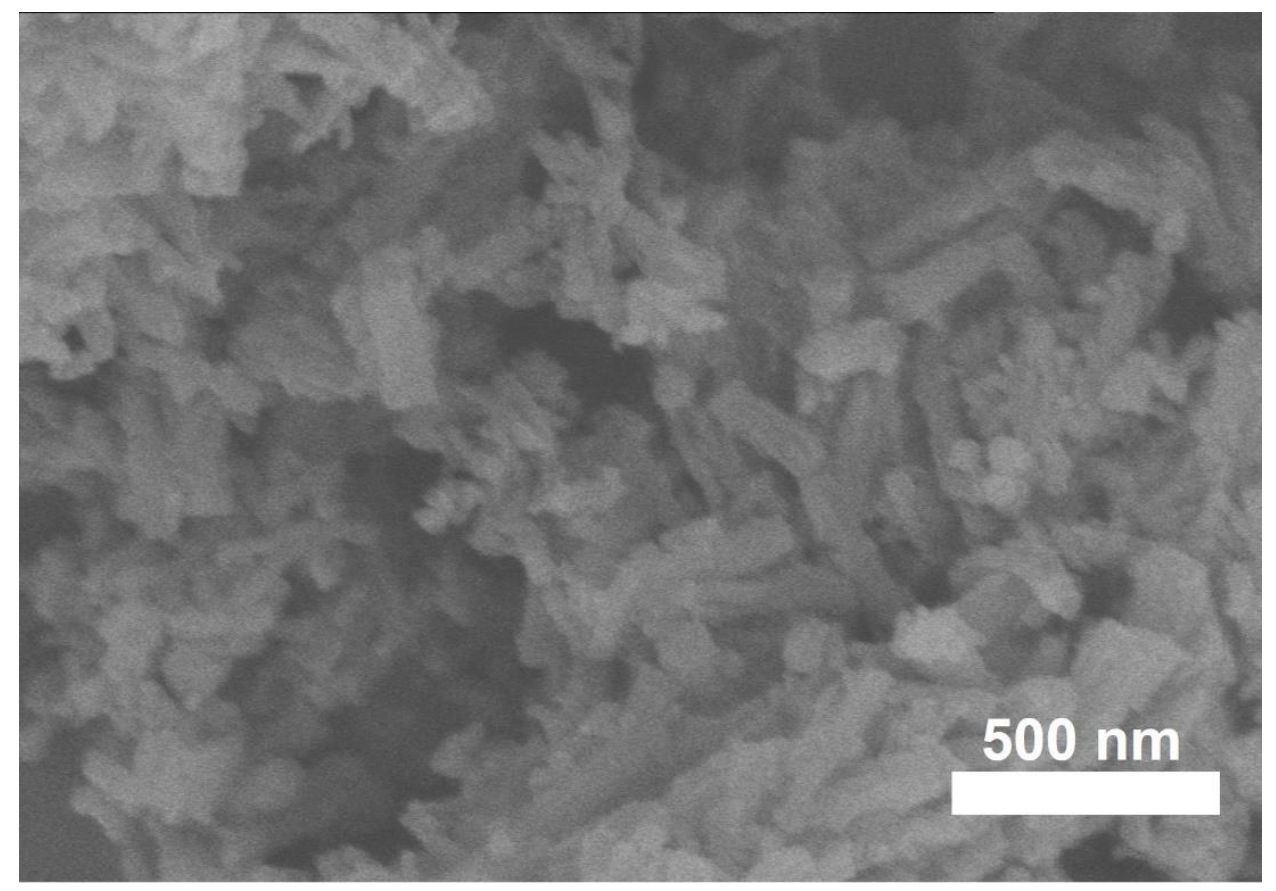

Figure S1. The scanning electron microscopy (SEM) image of TpTt.

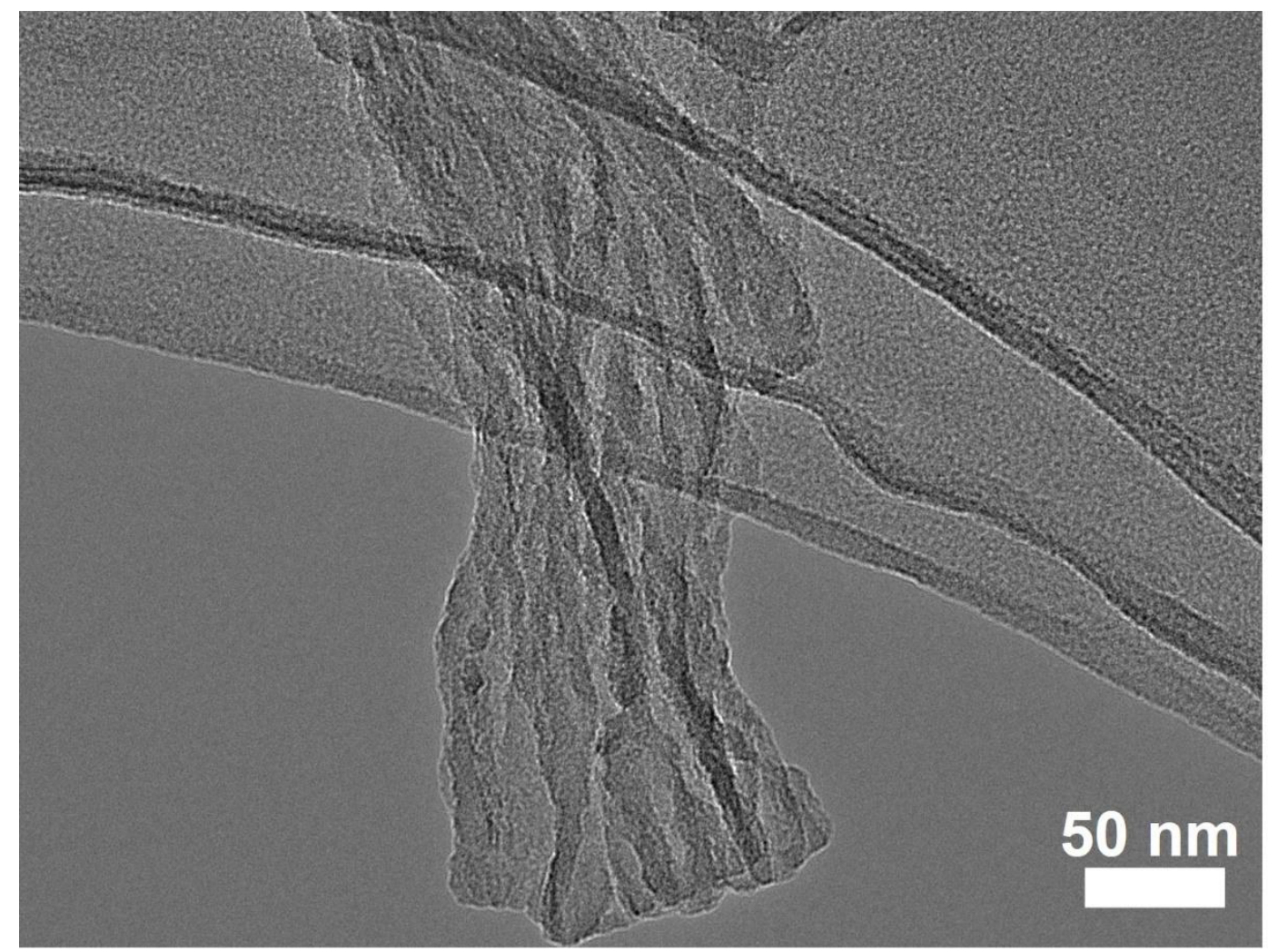

Figure S2. The transmission electron microscopy (TEM) image of TpTt. 


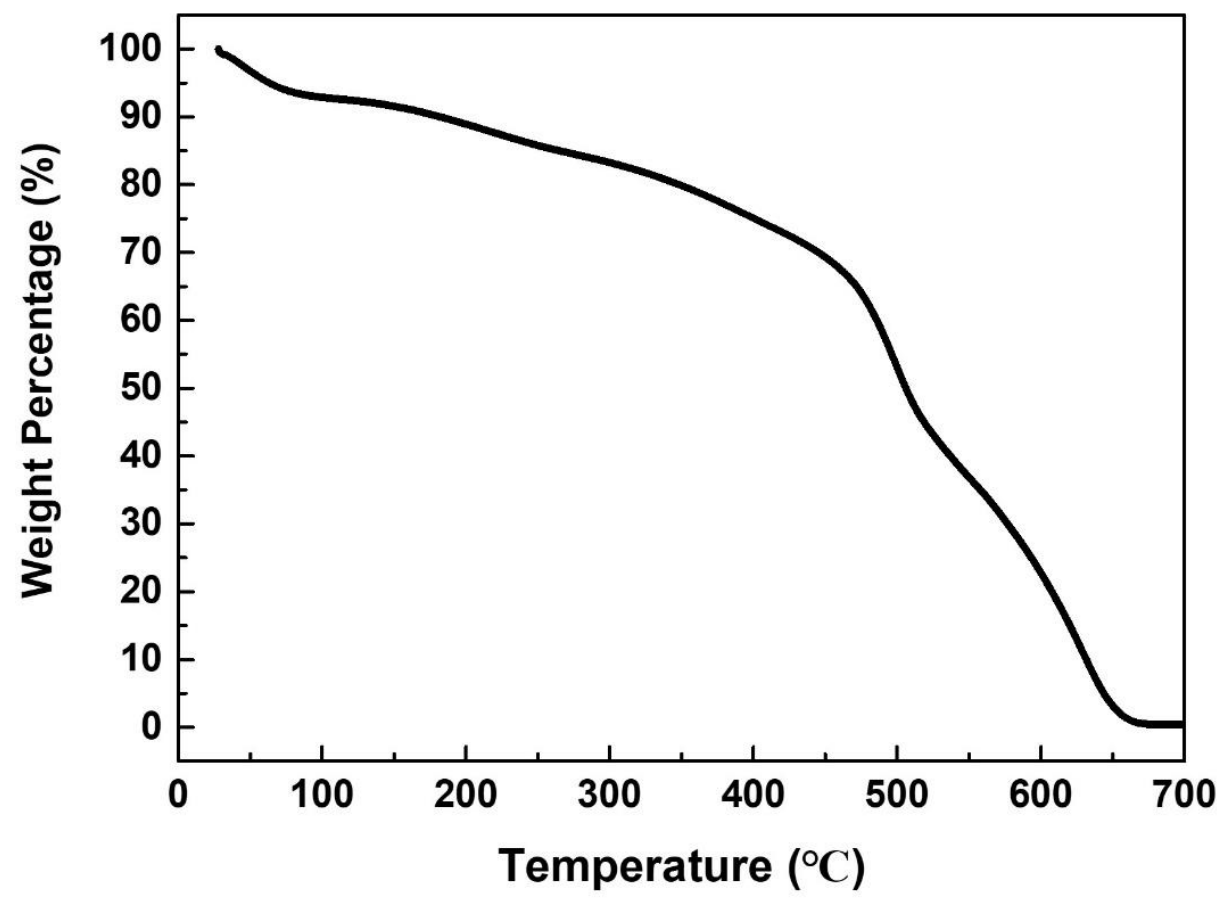

Figure S3. The thermogravimetric analysis curve of TpTt.
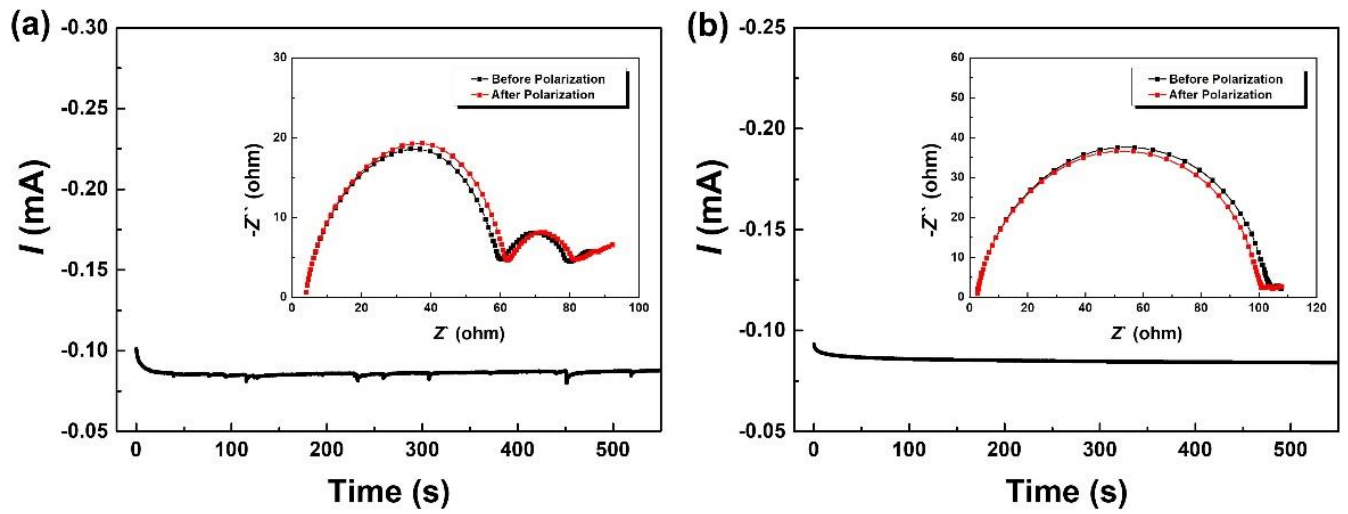

Figure S4. The potentiostatic DC polarization and AC impedance spectra of symmetric batteries (a) with and (b) without TpTt-coating separators. 

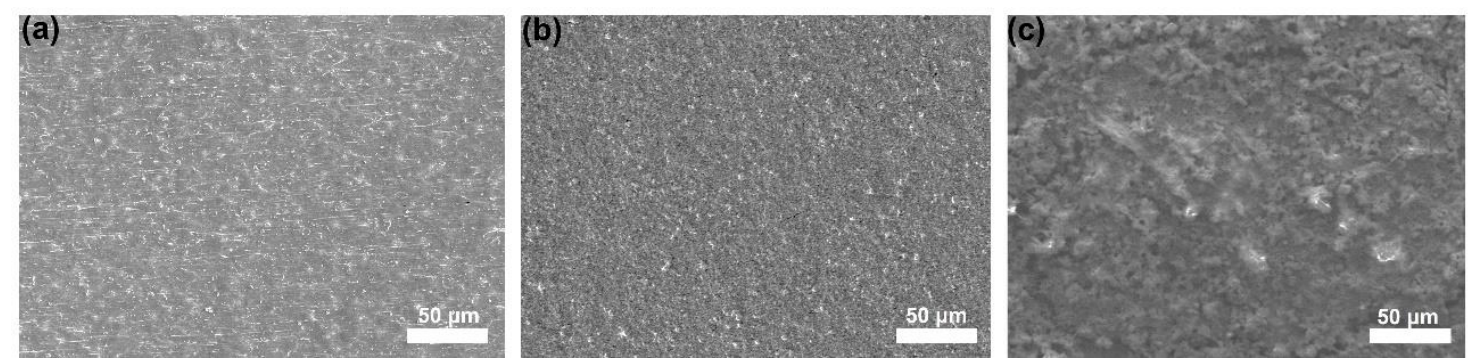

Figure S5. The SEM images of (a) pristine $\mathrm{Cu}$ foils, (b) $\mathrm{TpTt}$ and (c) $\mathrm{Tz}$ coated $\mathrm{Cu}$ foils. 


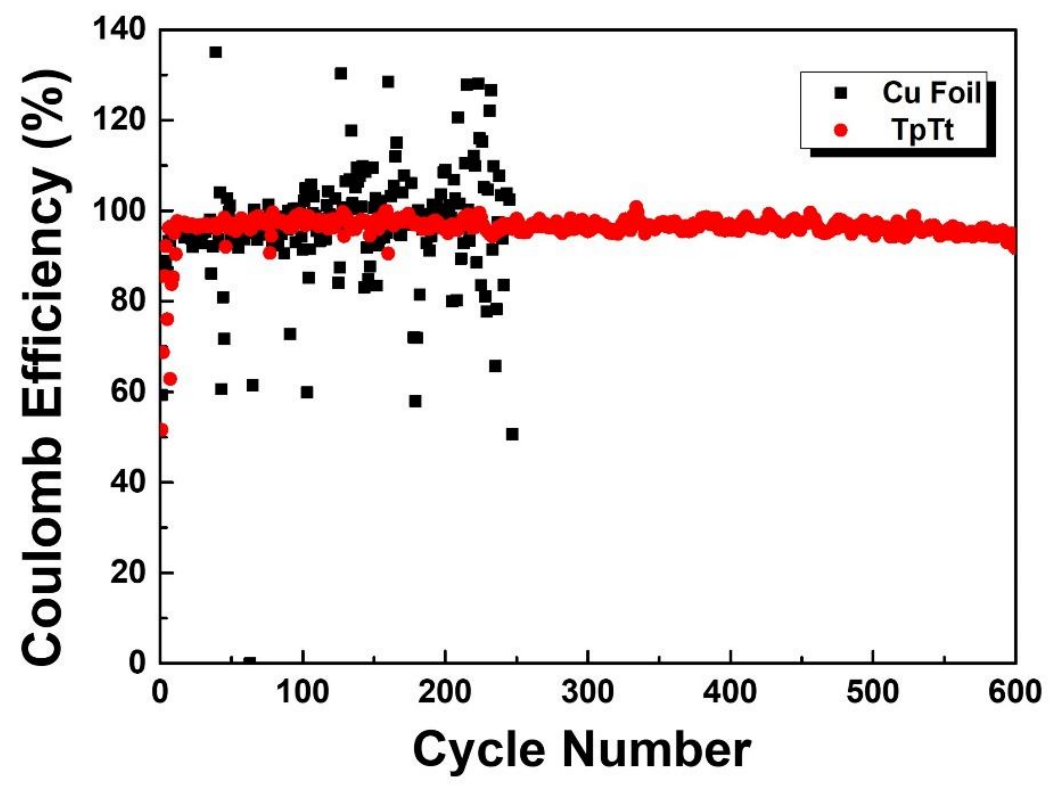

Figure S6. The Coulomb efficiency (CE) comparison of the $\mathrm{Li}-\mathrm{Cu}$ batteries at a current density of $0.5 \mathrm{~mA} \mathrm{~cm}^{-2}$ and a capacity of $0.5 \mathrm{mAh} \mathrm{cm}^{-2}$.

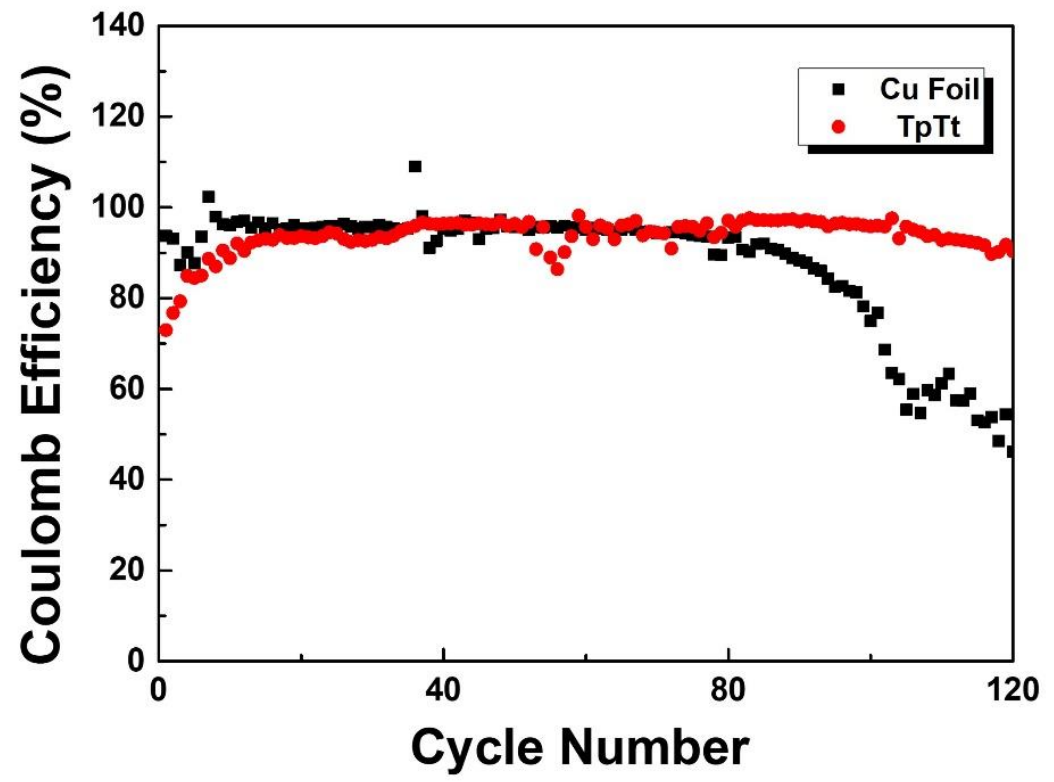

Figure S7. The $\mathrm{CE}$ behavior of $\mathrm{Li}-\mathrm{Cu}$ batteries based on $\mathrm{TpTt}$ and bare current collectors at current density of $2 \mathrm{~mA} \mathrm{~cm}^{-2}$ with capacity of $2 \mathrm{mAh} \mathrm{cm}^{-2}$. 


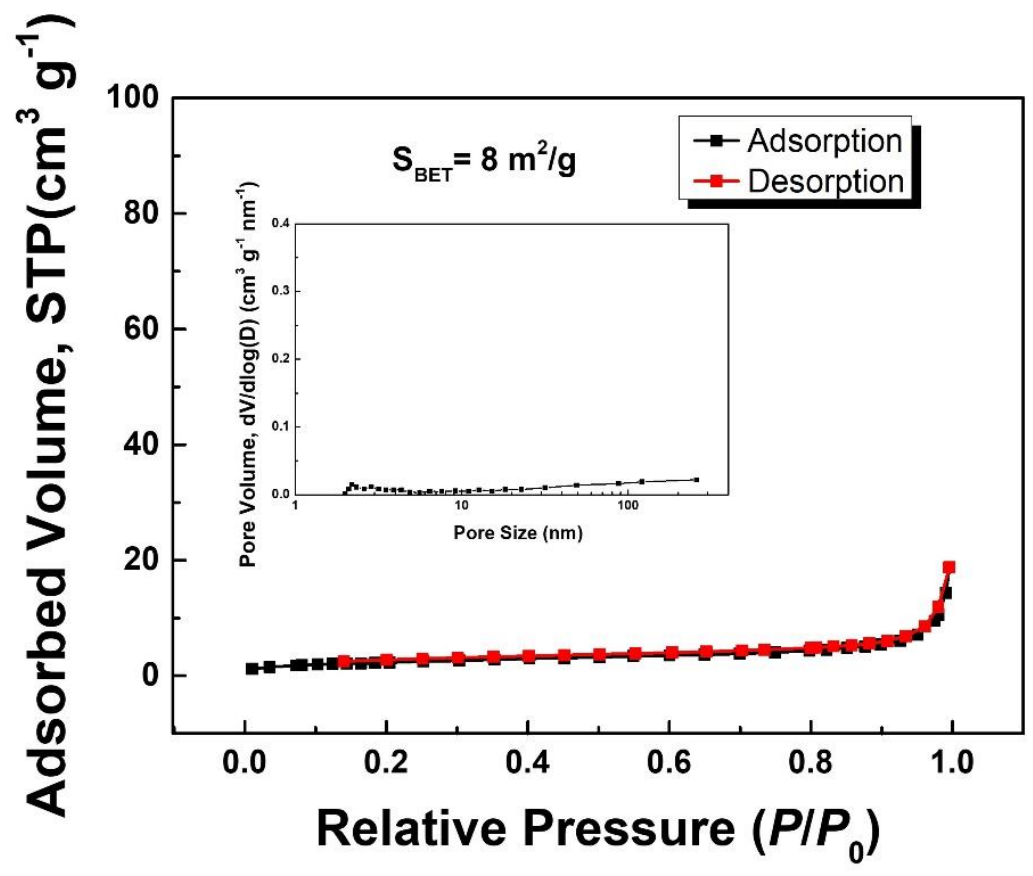

Figure S8. The $\mathrm{N}_{2}$ sorption isotherm of Tz. The inset figure is the pore size distribution of Tz.

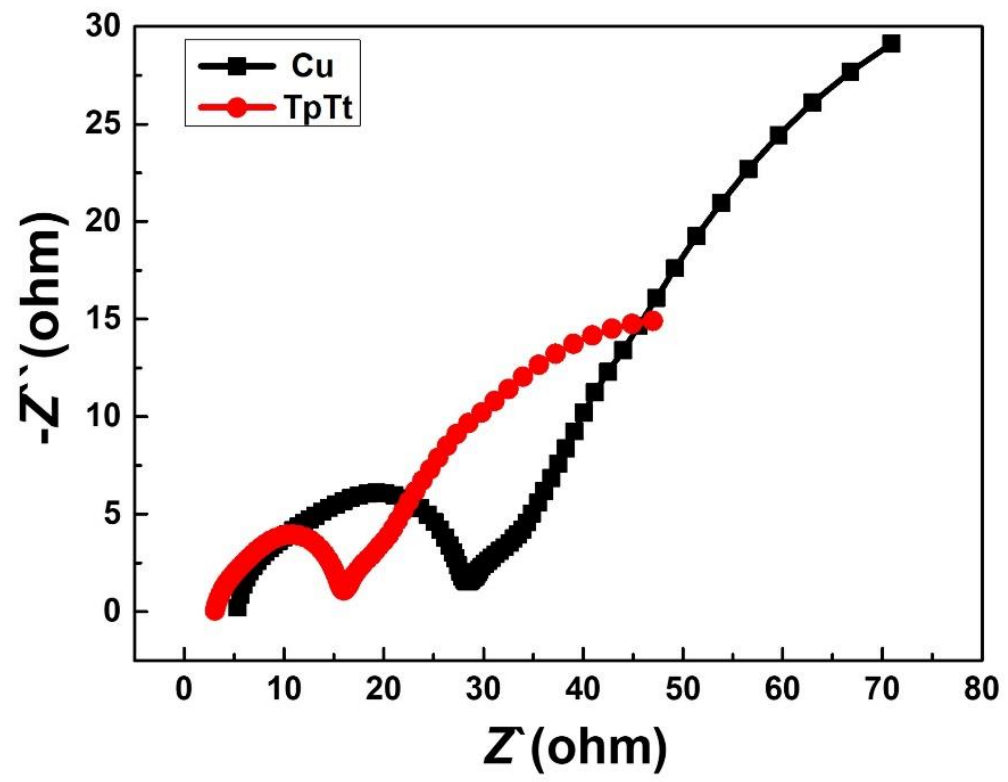

Figure S9. Comparison of Nyquist plots of the $\mathrm{Li}-\mathrm{Cu}$ batteries with and without $\mathrm{TpTt}$ after cycling. 


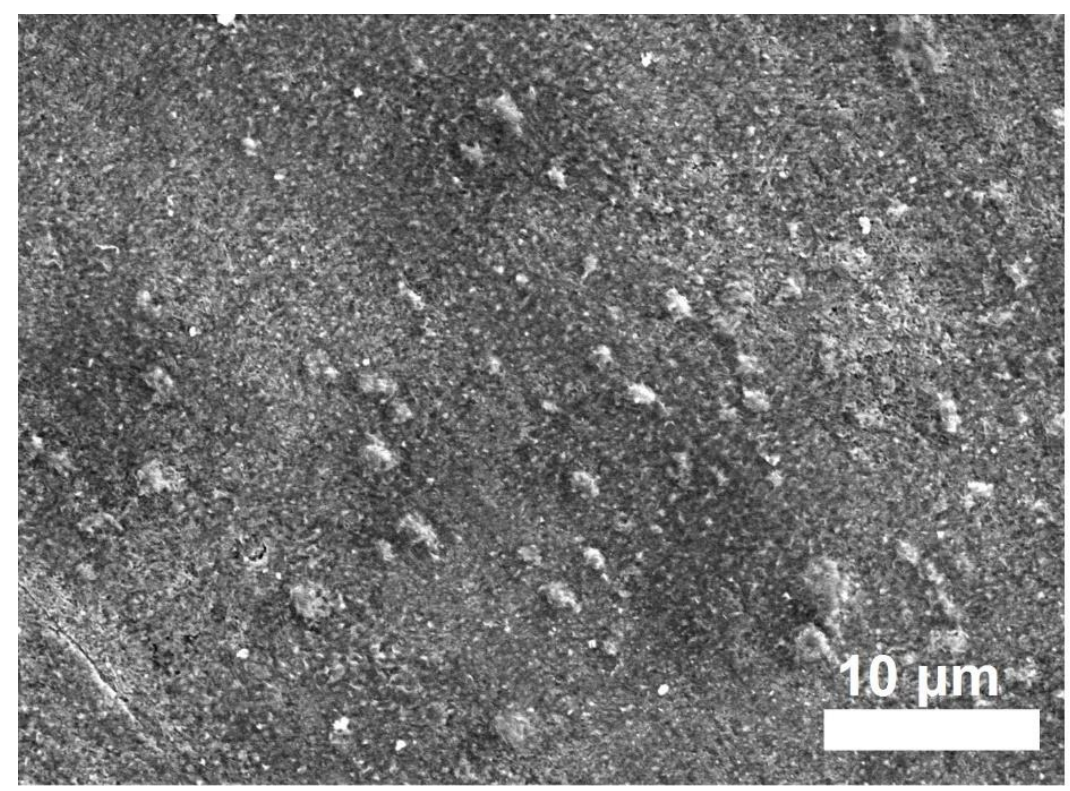

Figure S10. The SEM image of Li nucleation on $\mathrm{Cu}$ foils. 

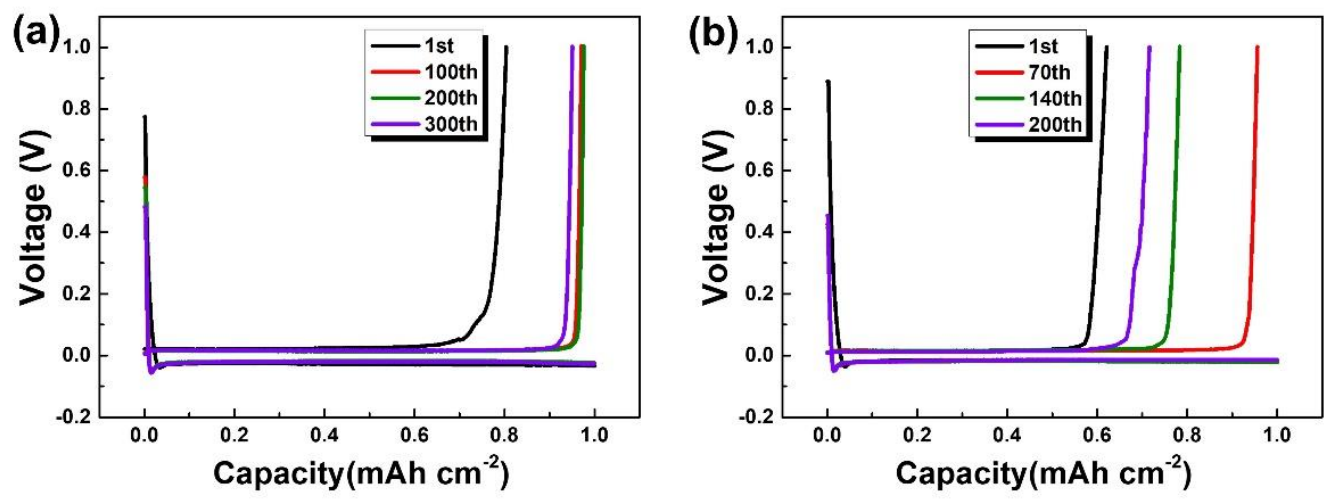

Figure S11. The voltage profiles of $\mathrm{Li}-\mathrm{Cu}$ batteries based on (a) $\mathrm{TpTt}$ and (b) bare current collectors at current density of $1 \mathrm{~mA} \mathrm{~cm}^{-2}$ with capacity of $1 \mathrm{mAh} \mathrm{cm} \mathrm{cm}^{-2}$ over 300 and 200 cycles respectively.

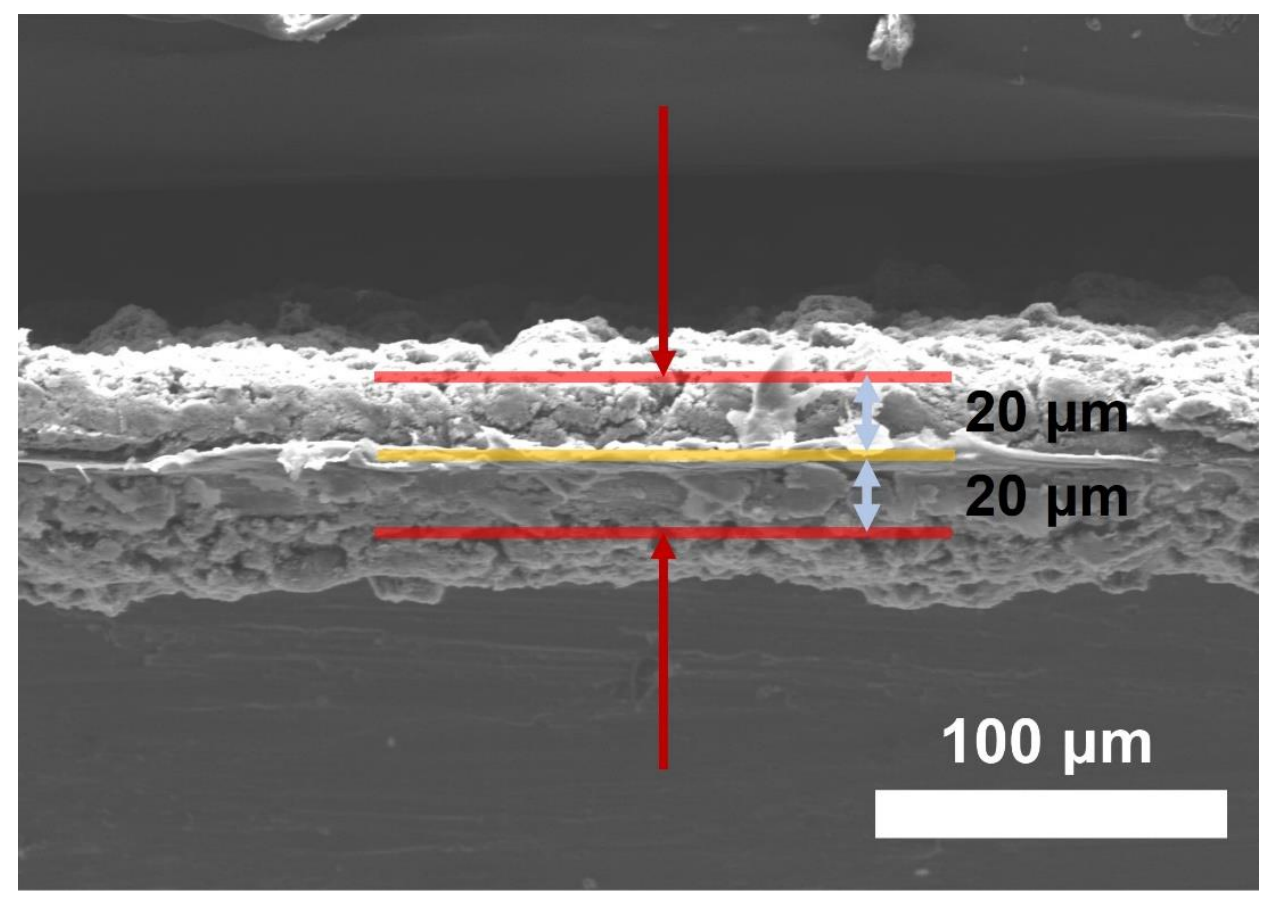

Figure S12. The SEM image of coated separators viewed in cross side. 


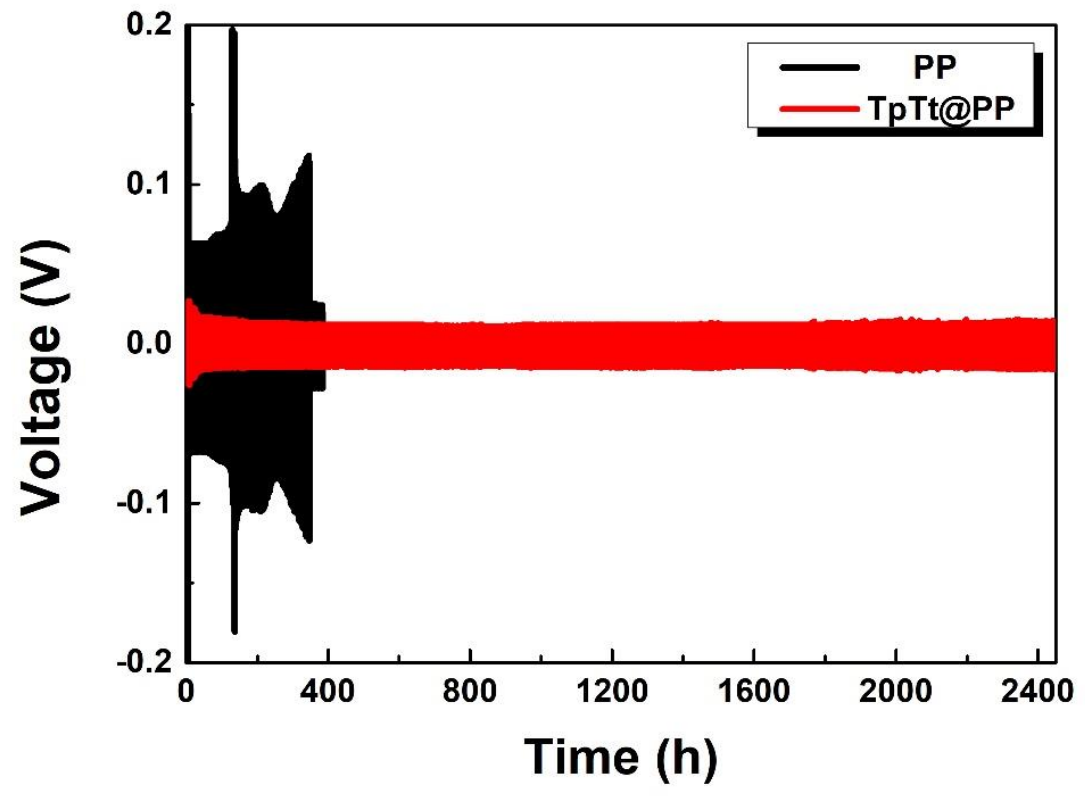

Figure S13. Comparison of the cycling stability of the symmetrical cells with and without TpTt coated separators at a current density of $0.5 \mathrm{~mA} \mathrm{~cm}{ }^{-2}$.

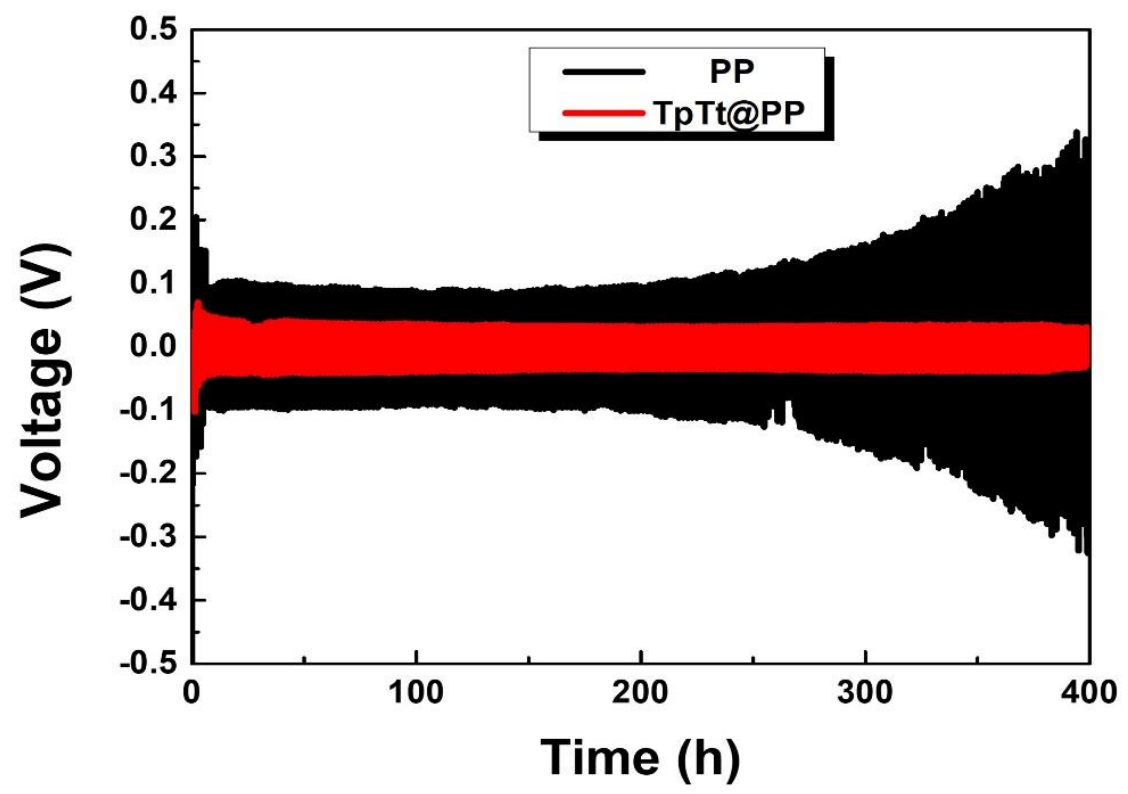

Figure S14. Comparison of the cycling stability of the symmetrical cells with and without TpTt coated separators at a current density of $2 \mathrm{~mA} \mathrm{~cm}{ }^{-2}$. 

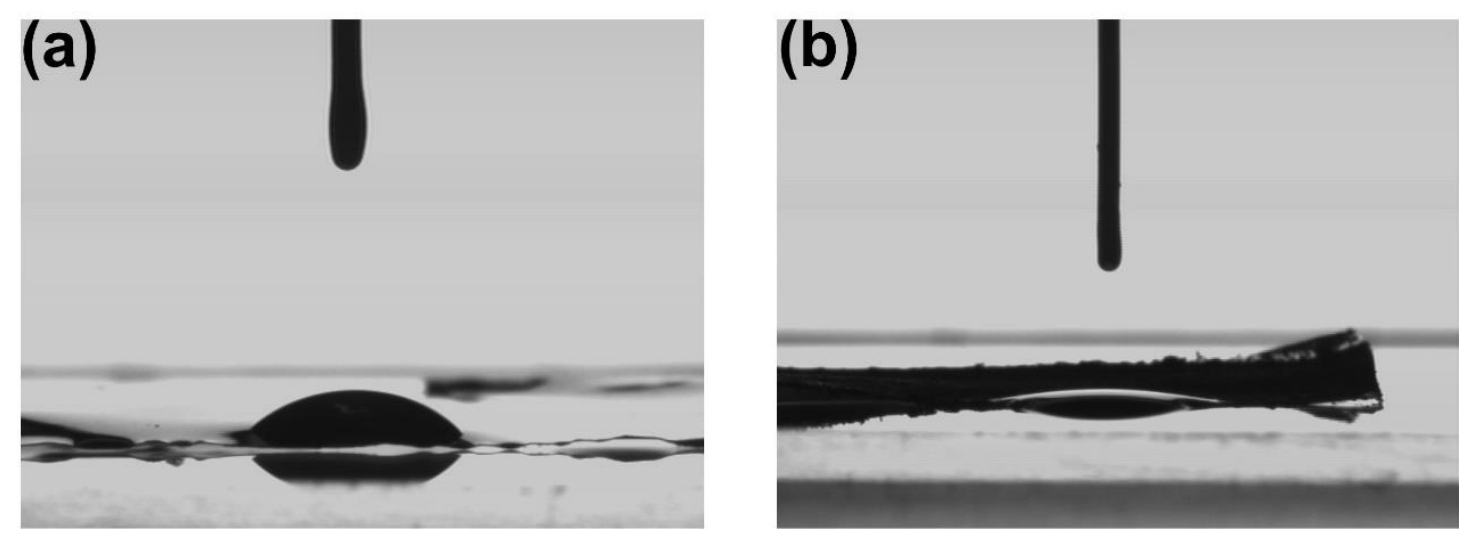

Figure S15. Comparison of the electrolyte wettability for (a) PP membrane and (b) TpTt-coated PP membrane. 


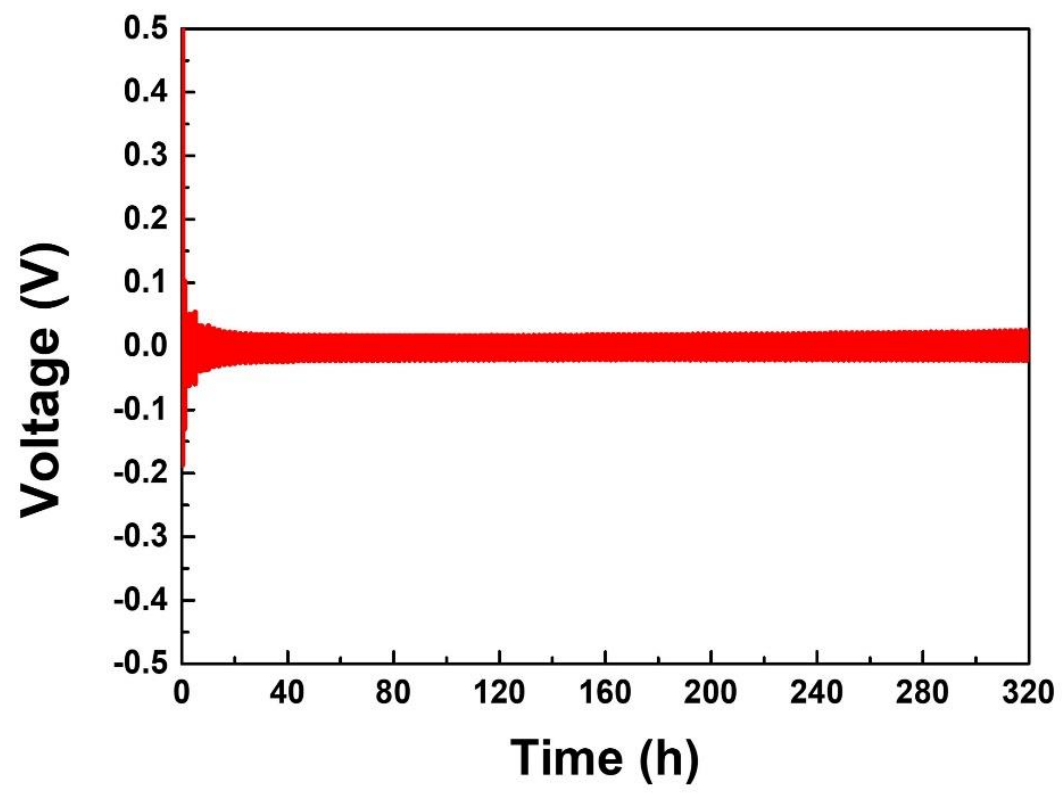

Figure S16. Cycling stability of the symmetrical Li@TpTt|Li@TpTt cell at a current density of $1 \mathrm{~mA} \mathrm{~cm}^{-2}$.

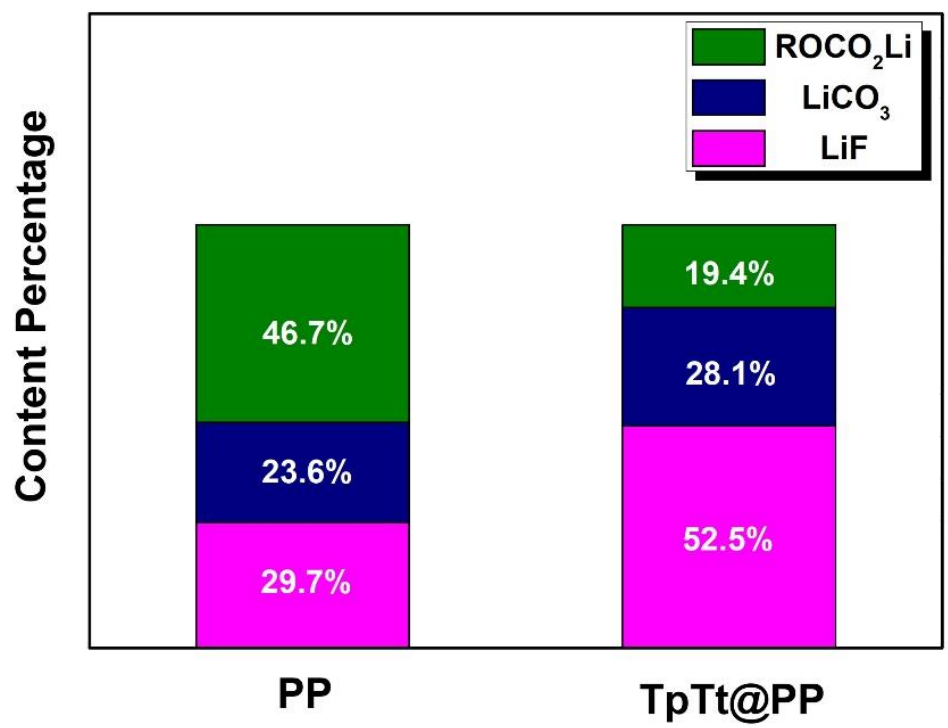

Figure S17. Comparison of solid electrolyte interphase components in half batteries with and without $\mathrm{TpTt}$ protecting layers after cycling. 


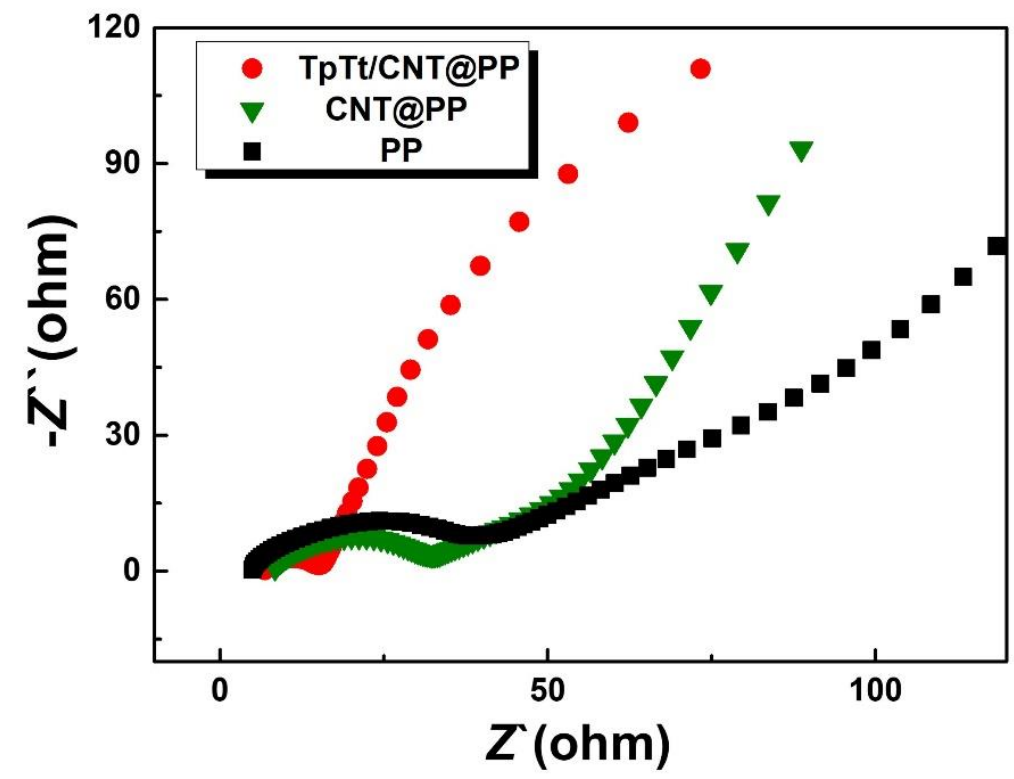

Figure S18. The Nyquist plots of Li-S batteries with TpTt/CNT@PP, CNT@PP, and PP separators after cycling. 


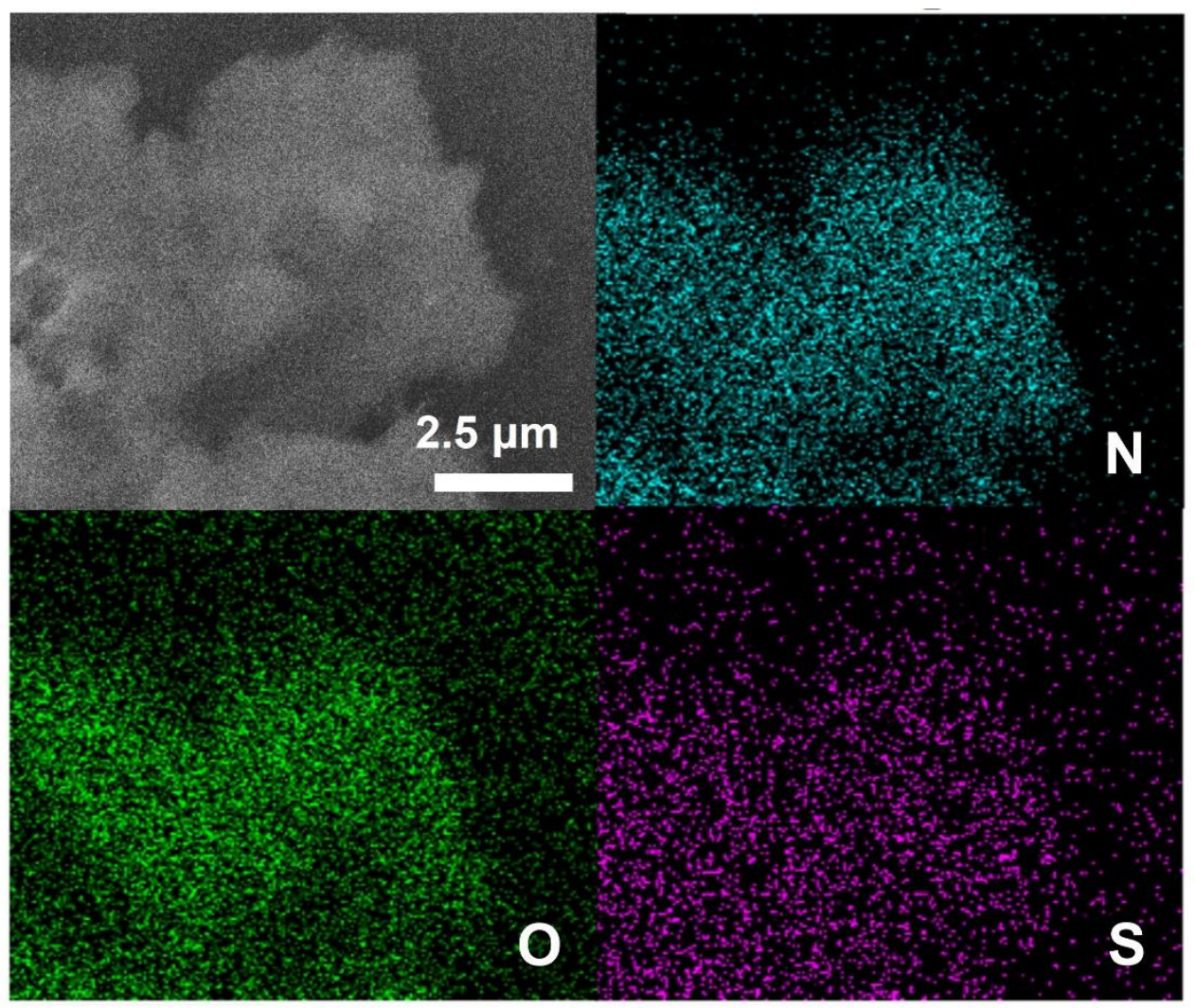

Figure S19. The elements mapping of TpTt after absorbing $\mathrm{Li}_{2} \mathrm{~S}_{6}$.

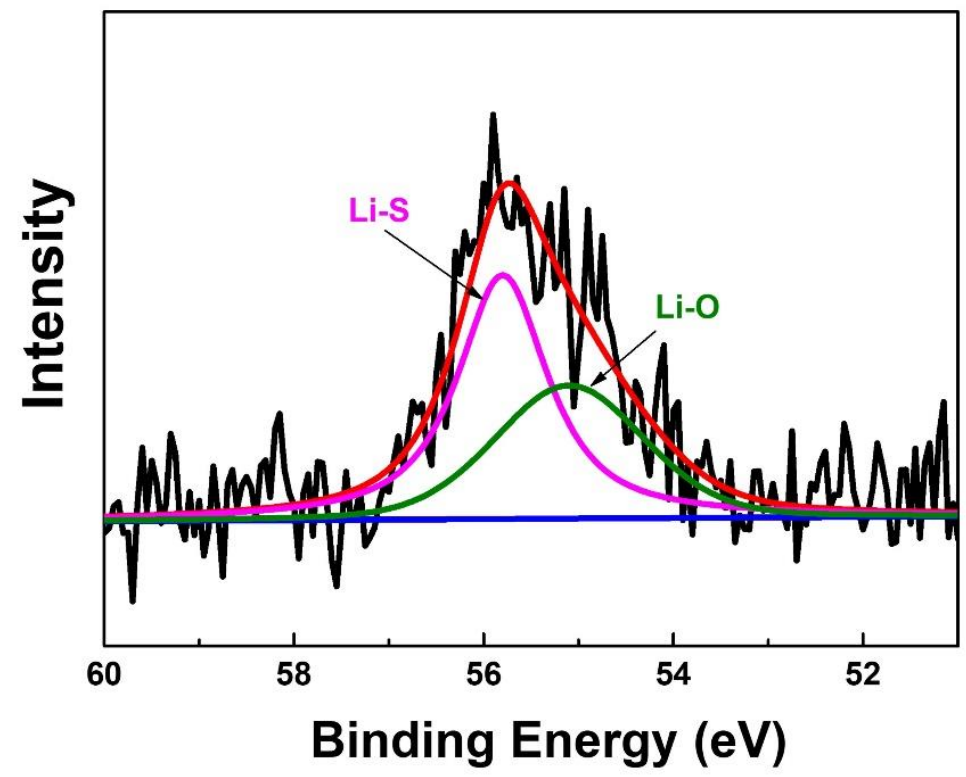

Figure S20. The Li 1s spectra of TpTt after absorbing $\mathrm{Li}_{2} \mathrm{~S}_{6}$. 


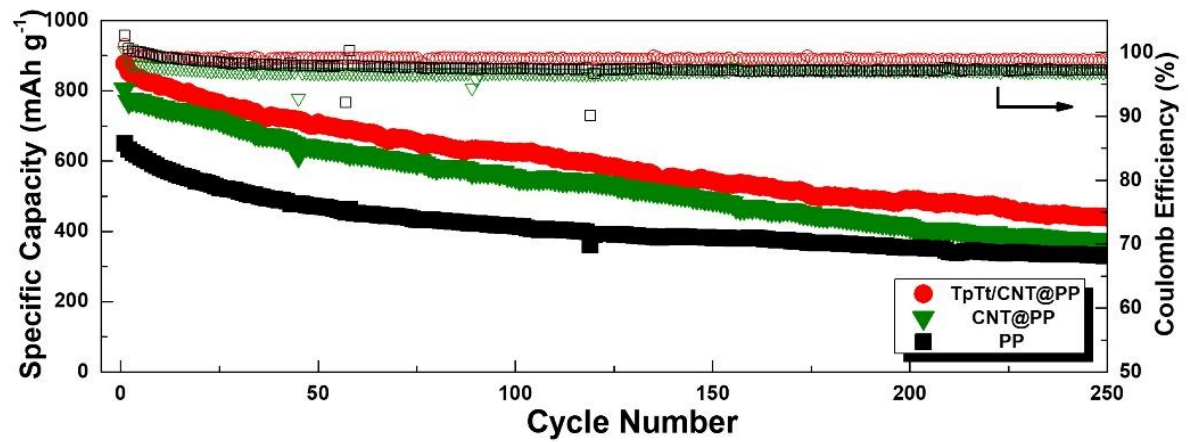

Figure S21. The long-term cycling performances of Li-S batteries with TpTt/CNT@PP, CNT@PP, and bare separators at $0.25 \mathrm{C}$. 


\section{REFERENCES}

[S1] Shen, K.; Wang, Z.; Bi, X.; Ying, Y.; Zhang, D.; Jin, C.; Hou, G.; Cao, H.; Wu, L.; Zheng, G.; Tang, Y.; Tao, X.; Lu, J. Magnetic Field-Suppressed Lithium Dendrite Growth for Stable Lithium-Metal Batteries. Adv. Energy Mater. 2019, 9, 1900260.

[S2] Jia, W.; Wang, Q.; Yang, J.; Fan, C.; Wang, L.; Li, J. Pretreatment of Lithium Surface by Using Iodic Acid $\left(\mathrm{HIO}_{3}\right)$ to Improve Its Anode Performance in Lithium Batteries. ACS Appl. Mater. Interfaces 2017, 9, 7068-7074.

[S3] He, Y.; Zhang, Y.; Li, X.; Lv, Z.; Wang, X.; Liu, Z.; Huang, X. A Novel ZnO-Based Inorganic/organic Bilayer with Low Resistance for Li Metal Protection. Energy Storage Mater. 2018, 14, 392-401.

[S4] Wang, L.; Wang, Q.; Jia, W.; Chen, S.; Gao, P.; Li, J. Li Metal Coated with Amorphous $\mathrm{Li}_{3} \mathrm{PO}_{4}$ via Magnetron Sputtering for Stable and Long-Cycle Life Lithium Metal Batteries. J. Power Sources 2017, 342, 175-182.

[S5] Liu, S.; Zhang, X.; Li, R.; Gao, L.; Luo, J. Dendrite-Free Li Metal Anode by Lowering Deposition Interface Energy with $\mathrm{Cu}_{99} \mathrm{Zn}$ Alloy Coating. Energy Storage Mater. 2018, 14, 143-148.

[S6] Liu, F.; Xiao, Q.; Wu, H. Bin; Shen, L.; Xu, D.; Cai, M.; Lu, Y. Fabrication of Hybrid Silicate Coatings by a Simple Vapor Deposition Method for Lithium Metal Anodes. Adv. Energy Mater. 2018, 8, 1701744.

[S7] Xu, J.; Tang, W.; Yu, F.; Zhao, S.; Niu, D.; Zhang, X.; Xin, Z.; Chen, R. Trimming the $\pi$ Bridge of Microporous Frameworks for Bidentate Anchoring of Polysulfides to Stabilize Lithium-Sulfur Batteries. J. Mater. Chem. A 2020, 8, 19001-19010.

[S 8 ] Bae, J.; Qian, Y.; Li, Y.; Zhou, X.; Goodenough, J. B.; Yu, G. Polar 
Polymer-Solvent Interaction Derived Favorable Interphase for Stable Lithium Metal Batteries. Energy Environ. Sci. 2019, 12, 3319-3327.

[S9] Liu, J.; Xu, R.; Yan, C.; Yuan, H.; Ding, J.-F.; Xiao, Y.; Yuan, T.-Q.; Huang, J.-Q. In Situ Regulated Solid Electrolyte Interphase via Reactive Separators for Highly Efficient Lithium Metal Batteries. Energy Storage Mater. 2020, 30, 27-33.

[S10] Ma, C.; Feng, Y.; Liu, X.; Yang, Y.; Zhou, L.; Chen, L.; Yan, C.; Wei, W. Dual-Engineered Separator for Highly Robust, All-Climate Lithium-Sulfur Batteries. Energy Storage Mater. 2020, 32, 46-54.

[S11] Tang, W.; Yin, X.; Kang, S.; Chen, Z.; Tian, B.; Teo, S. L.; Wang, X.; Chi, X.; Loh, K. P.; Lee, H.-W.; Zheng, G. W. Lithium Silicide Surface Enrichment: A Solution to Lithium Metal Battery. Adv. Mater. 2018, 30, 1801745.

[S12] Xu, Q.; Yang, X.; Rao, M.; Lin, D.; Yan, K.; Du, R. A.; Xu, J.; Zhang, Y.; Ye, D.; Yang, S.; Zhou, G.; Lu, Y.; Qiu, Y. High Energy Density Lithium Metal Batteries Enabled by a Porous graphene/ $\mathrm{MgF}_{2}$ Framework. Energy Storage Mater. 2020, 26, 73-82.

[S13] Li, N.; Zhang, K.; Xie, K.; Wei, W.; Gao, Y.; Bai, M.; Gao, Y.; Hou, Q.; Shen, C.; Xia, Z.; Wei, B. Reduced-Graphene-Oxide-Guided Directional Growth of Planar Lithium Layers. Adv. Mater. 2020, 32, 1905573.

[S14] Li, D.; Zhang, S.; Zhang, Q.; Kaghazchi, P.; Qi, H.; Liu, J.; Guo, Z.; Wang, L.; Wang, Y. Pencil-Drawing on Nitrogen and Sulfur Co-Doped Carbon Paper: An Effective and Stable Host to Pre-Store Li for High-Performance Lithium-air Batteries. Energy Storage Mater. 2020, 26, 593-603.

[S15] Xu, Q.; Lin, J.; Ye, C.; Jin, X.; Ye, D.; Lu, Y.; Zhou, G.; Qiu, Y.; Li, W. Air-Stable and Dendrite-Free Lithium Metal Anodes Enabled by a Hybrid Interphase of 
$\mathrm{C}_{60}$ and Mg. Adv. Energy Mater. 2020, 10, 1903292.

[S16] Jiang, Y.; Jiang, J.; Wang, Z.; Han, M.; Liu, X.; Yi, J.; Zhao, B.; Sun, X.; Zhang, J. Li ${ }_{4.4} \mathrm{Sn}$ Encapsulated in Hollow Graphene Spheres for Stable Li Metal Anodes without Dendrite Formation for Long Cycle-Life of Lithium Batteries. Nano Energy 2020, 70, 104504.

[S17] Zhang, Y.; Wang, C.; Pastel, G.; Kuang, Y.; Xie, H.; Li, Y.; Liu, B.; Luo, W.; Chen, C.; Hu, L. 3D Wettable Framework for Dendrite-Free Alkali Metal Anodes. Adv. Energy Mater. 2018, 8, 180635.

[S18] Lee, D.; Sun, S.; Kwon, J.; Park, H.; Jang, M.; Park, E.; Son, B.; Jung, Y.; Song, T.; Paik, U. Copper Nitride Nanowires Printed Li with Stable Cycling for Li Metal Batteries in Carbonate Electrolytes. Adv. Mater. 2020, 32, 1905573.

[S19] Pathak, R.; Chen, K.; Gurung, A.; Reza, K. M.; Bahrami, B.; Pokharel, J.; Baniya, A.; He, W.; Wu, F.; Zhou, Y.; Xu, K.; Qiao, Q. Q. Dendrite-Free Lithium Deposition. Nature Commun. 2020, 11, 93. 